ANL-6667

Engineering and Equipment

(TID-4500, 19th Ed.)

AEC Research and

Development Report

\author{
ARGONNE NATIONAL LABORATORY \\ 9700 South Cass Avenue \\ Argonne, Illinois
}

\title{
A STUDY OF THE FLOW OF SATURATED FREON-11 THROUGH APERTURES AND SHORT TUBES \\ by
}

\author{
Hans K. Fauske and Tony C. Min \\ University of Minnesota \\ Reactor Engineering Division, ANL \\ and \\ Associated Midwest Universities
}

January 1963

This report is one of a series that describes heat-transfer and fluid-flow studies performed at Argonne under a program sponsored jointly by the Associated Midwest Universities and the Argonne National Laboratory.

The one earlier report in this series is ANL-6625.

\author{
Operated by The University of Chicago \\ under \\ Contract W-31-109-eng-38 \\ with the \\ U. S. Atomic Energy Commission
}




\section{DISCLAIMER}

This report was prepared as an account of work sponsored by an agency of the United States Government. Neither the United States Government nor any agency Thereof, nor any of their employees, makes any warranty, express or implied, or assumes any legal liability or responsibility for the accuracy, completeness, or usefulness of any information, apparatus, product, or process disclosed, or represents that its use would not infringe privately owned rights. Reference herein to any specific commercial product, process, or service by trade name, trademark, manufacturer, or otherwise does not necessarily constitute or imply its endorsement, recommendation, or favoring by the United States Government or any agency thereof. The views and opinions of authors expressed herein do not necessarily state or reflect those of the United States Government or any agency thereof. 


\section{DISCLAIMER}

Portions of this document may be illegible in electronic image products. Images are produced from the best available original document. 
TABLE OF CONTENTS

Page

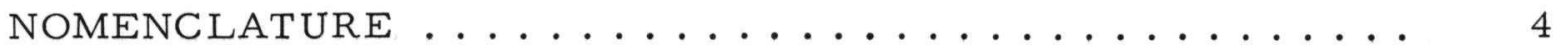

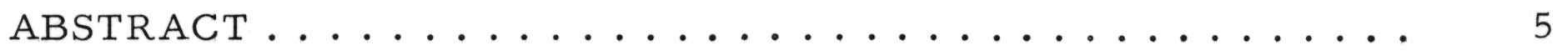

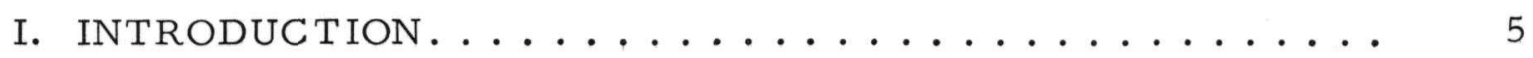

II. EXPERIMENT AL EQUIPMENT. .................. 6

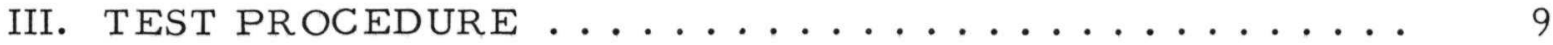

IV. ANALYSIS OF DATA AND APPLICATION. ........... 10

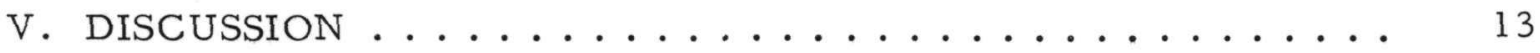

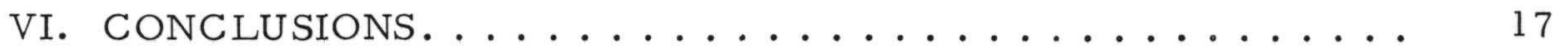

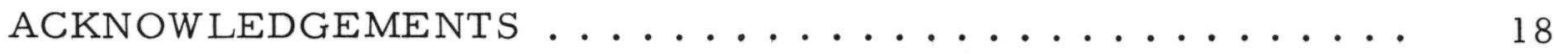

BIBLIOGRAPHY . . . . . . . . . . . . . . . . . . 19 


\section{LIST OF FIGURES}

No.

Title

Page

1. Diagram of the Experimental Equipment. . . . . . . . . . 7

2. View of the Experimental Equipment ............ 7

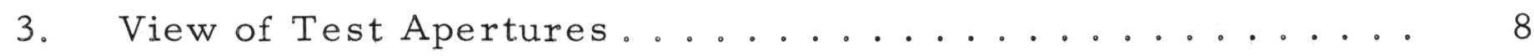

4. View of Test Tubes.......................... 8

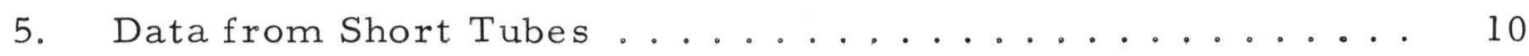

6. Correlation Number Determining the Occurrence of Single-

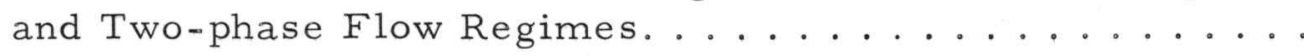

7. Correlation of Flow Rate and Length-to-diameter Ratio of

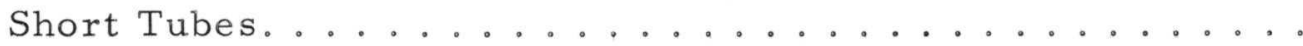

8. Euler Number Variation for Various Apertures . . . . . . . 12

9. Photograph Showing the Discharged Fluid from a Circular

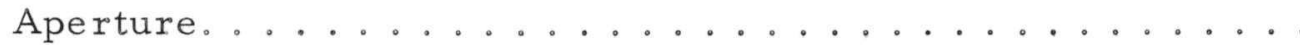

10. Photograph Showing the Discharged Fluid from an Eye-

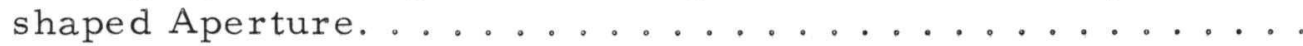

11. Photograph Showing the Discharged Fluid from a Tube with $\mathrm{L} / \mathrm{D} \sim 3$ and $\mathrm{Ca} \mathrm{C}^{\prime} \sim 8 \ldots \ldots \ldots$

12. Photograph Showing the Discharged Fluid from a Short Tube with a Modified Cavitation Number between 10 and 14....

13. Photograph Showing the Discharged Fluid from a Short Tube When Critical Flow Occurs ................ 


\section{NOMENCLATURE}

A

$\mathrm{Ca}^{\prime}=\frac{2 \mathrm{~g} \Delta \mathrm{P}}{\rho_{\mathrm{i}} \mathrm{U}^{2}}(\mathrm{~L} / \mathrm{D})$

D

$E u=\frac{Q}{A \sqrt{2 g h}}$

g

$g_{C}$

h

L

$\mathrm{P}$

$\mathrm{P}_{\mathrm{e}}$

$\mathrm{P}_{\mathrm{b}}$

$\mathrm{P}_{\mathrm{i}}$

Q

$\mathrm{U}=\mathrm{Q} / \mathrm{A}$

$\triangle P$

$\rho$

$\rho_{\mathrm{i}}$ cross-sectional area of the opening of the vessel, $\mathrm{ft}^{2}$

modified cavitation number, dimensionless

diameter or equivalent diameter, ft

Euler number, dimensionless

acceleration of gravity, $\mathrm{ft} / \mathrm{sec}^{2}$

conversion factor, $32.2\left(1 b_{m} \mathrm{ft}\right) /\left(1 b_{f} \sec ^{2}\right)$

head of fluid, ft

length of tube, $\mathrm{ft}$

local pressure, $1 b_{f} / \mathrm{ft}^{2}$

exit pressure, $1 b_{f} / \mathrm{ft}^{2}$

back pressure, $1 b_{f} / \mathrm{ft}^{2}$

initial pressure of fluid inside the vessel at the level of the exit, $1 b_{f} / \mathrm{ft}^{2}$

discharge rate of fluid, $\mathrm{ft}^{3} / \mathrm{sec}$

average velocity of the fluid in the vessel flowing out, $\mathrm{ft} / \mathrm{sec}$

pressure difference, $\mathrm{P}_{\mathrm{i}}-\mathrm{P}_{\mathrm{e}}$ for two-phase flow, $\mathrm{P}_{\mathrm{i}}-\mathrm{P}_{\mathrm{b}}$ for single-phase flow, $1 \mathrm{~b}_{\mathrm{f}} / \mathrm{ft}^{2}$

density of the fluid, $1 b_{\mathrm{m}} / \mathrm{ft}^{3}$

initial density of the saturated or subcooled fluid in the vessel, $1 \mathrm{bm} / \mathrm{ft}^{3}$ 


\title{
A STUDY OF THE FLOW OF SATURATED FREON-11 THROUGH APERTURES AND SHORT TUBES
}

\author{
by
}

Hans K. Fauske and Tony C. Min

\begin{abstract}
An experimental study on the discharge rates of saturated and subcooled Freon-11 through apertures and short tubes is reported. The experiment covered a range of modified cavitation numbers between 0 and 500, length-to-diameter ratios of small diameter tubes between 2 and 55, and sharpedge apertures of nine different geometric configurations.

It was found that below the modified cavitation number of 10 the fluid exhibits completely metastable single-phase flow. When the modified cavitation number exceeds 14, twophase critical flow may exist. In the range of modified cavitation numbers between 10 and 14, unstable transitional flow occurs (alternating single- and two-phase flow).

Euler numbers for the apertures of various configurations, including square, rectangular, and eye-shaped, were found to be in the same order of magnitude as those for circular shapes. The triangular orifices were found to possess higher Euler numbers and the W-shaped orifices lower than the circular ones.
\end{abstract}

\section{INTRODUCTION}

An upsurge of interest has recently taken place in order to clarify the many problems associated with various containment systems for nuclear reactors. One of the most valuable tools that a containment designer can possess is a method for predicting accurately the rate of release of coolant under a variety of prototype conditions. To obtain such a tool would involve basic studies of flow of saturated fluids through various sizes of pipes, ducts, apertures, etc., going from high-to low-pressure systems, and including steady-state as well as highly transient flows. This problem becomes naturally tied to a phenomenon called critical flow.

Much experimental work regarding the critical phenomenon in circular flow passages of considerable lengths ( $>10$ in.) has appeared in the past ten years. (1-7) Experimental data of basic value exist, however, only up to about 400 psia (critical pressure). 
A theoretical model has been presented that shows substantial agreement with the se data.(1) As to the flow of saturated fluid through an aperture and short tube, some related experimental investigations are available, $(8,9)$ but the results are not sufficient to develop the necessary criteria for determining single-phase and two-phase flow regimes. Simpson and Silver(10) recently proposed a homogeneous nonequilibrium flow model to describe the saturated or supersaturated fluid through ducts. Another theoretical paper by Isbin and Gavalas (11) proposes a two-phase metastable or a two-phase growing-bubble homogeneous model for describing flow through an aperture.

However, the fundamentals upon which these models are formed may not simulate the actual physical process. It is strongly believed that critical flows in straight tubes of considerable lengths differ significantly from the flow from a sudden break in the vessel containing highly pressurized saturated fluid. This last example may be a more realistic picture of what might happen in a nuclear reactor assembly in the case of an accident. The dependence of critical flow rates from different shaped flow passages is at present not clear. Perhaps the most important question to clarify is, "does one obtain critical flow when a sudden break in the cooling system of a reactor occurs?" If so, to what extent? Is the fluid leaving the break in phys ical equilibrium, or completely or partially metastable? This is very important inasmuch as the flow rate is very sensitive to the compressibility of the fluid, which is determined by the above phenomenon.

In order to throw some light on the se various existing uncertainties, an extensive program has been initiated at Argonne National Laboratory. In this report is shown how answers to some of the se questions can be obtained from a basic and simple laboratory experiment.

\section{EXPERIMENTAL EQUIPMENT}

The test apparatus used in these experiments consisted of a vessel, test section, vacuum pump, and a condenser (see Figs. 1 and 2). A rectangular vessel, $8 \times 12 \times 33$ in., was made of $\frac{3}{8}$-in.-thick Lucite plates. At the top of the vessel a pressure gauge and a vent, and at the bottom a drain pipe with a valve, were provided. The vessel was connected to the pump through a 2 -in.-ID Pyrex tube after a $90^{\circ}$ turn. The test section was located between two Lucite flanges, one connected to an opening, 3 in. in diameter, in a wall of the vessel and the other to the Pyrex tube.

In the tests of apertures, the test sections were Lucite disks having apertures of various rupture configurations in the center. Samples of these are shown in Fig. 3. The short tubes shown in Fig. 4 were made of stainless steel and were threaded to the center of the Lucite disks to replace the aperture in the case of tests of short tubes. The outlet end of 


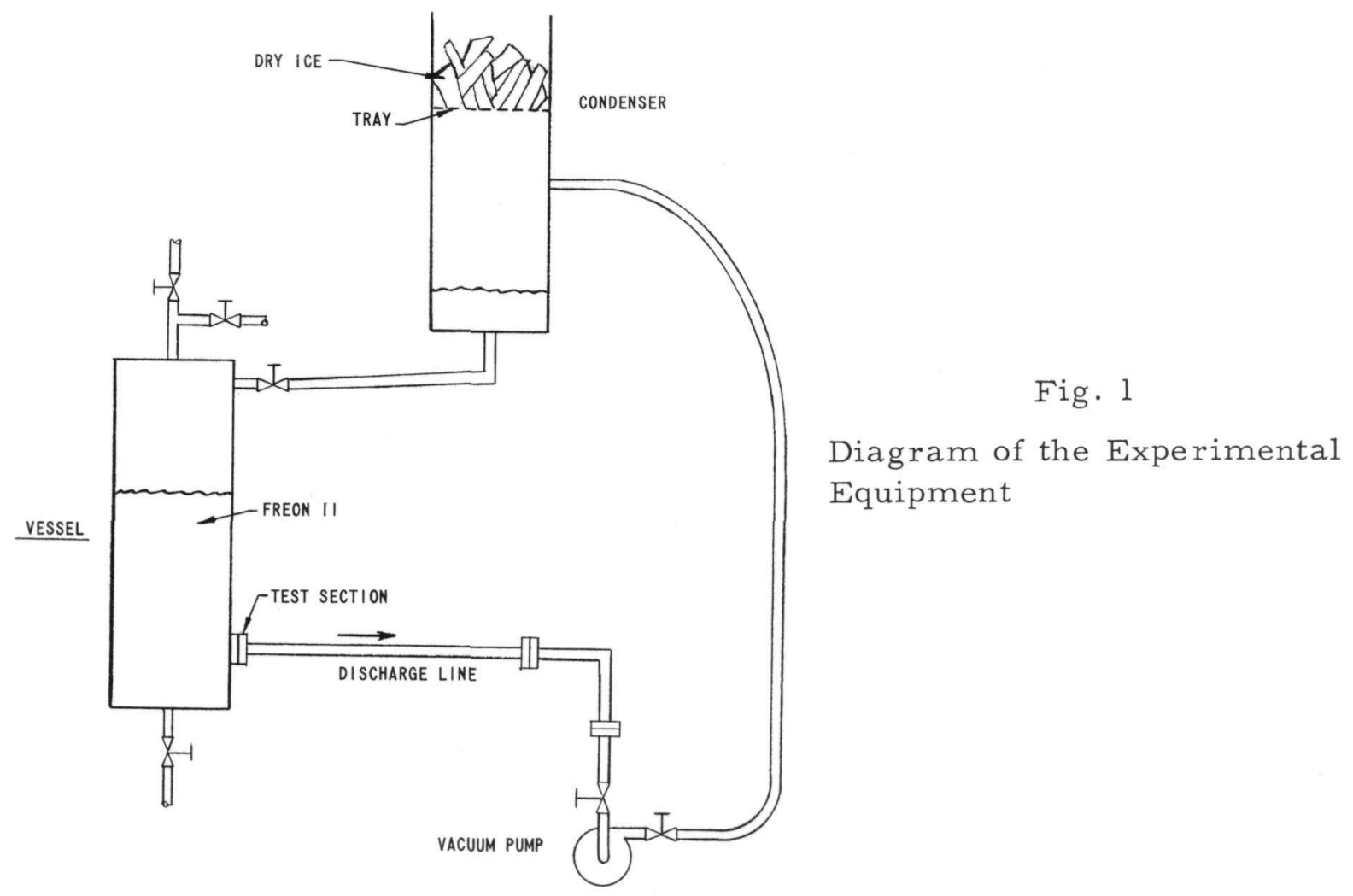

Fig. 2

View of the Experimental Equipment

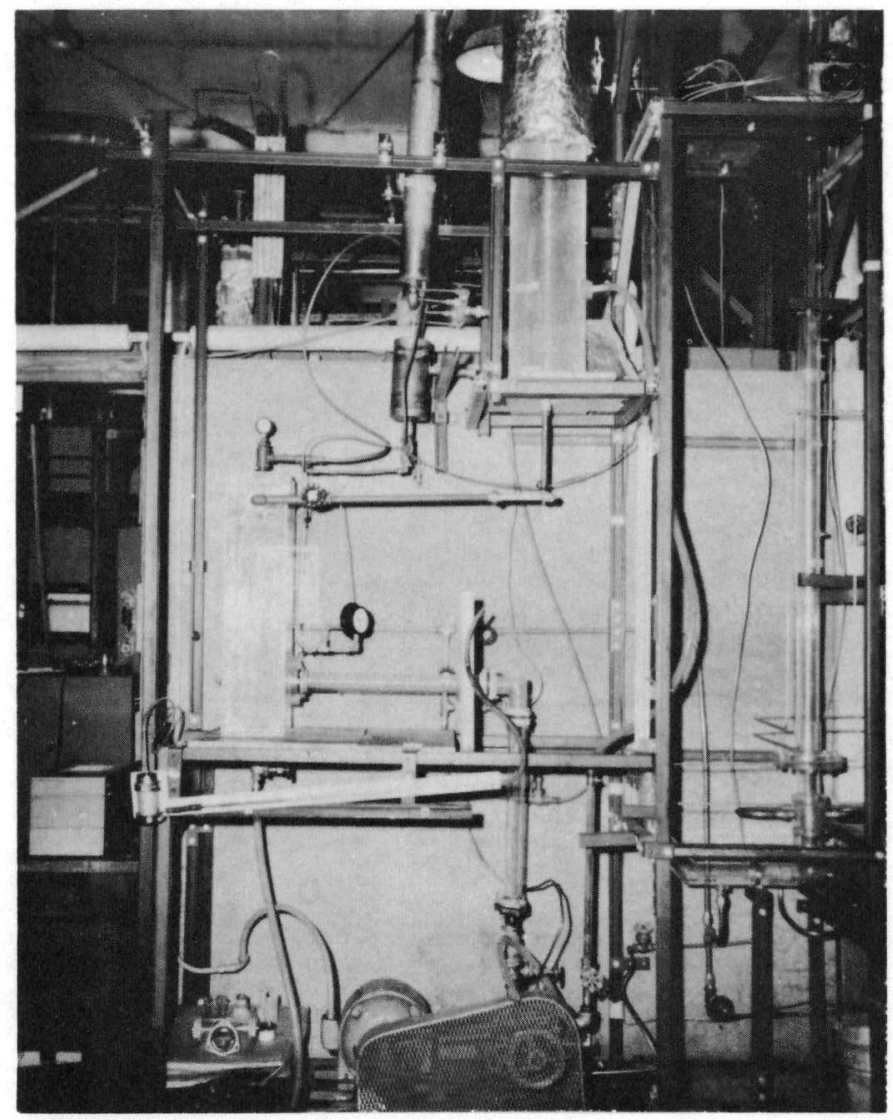




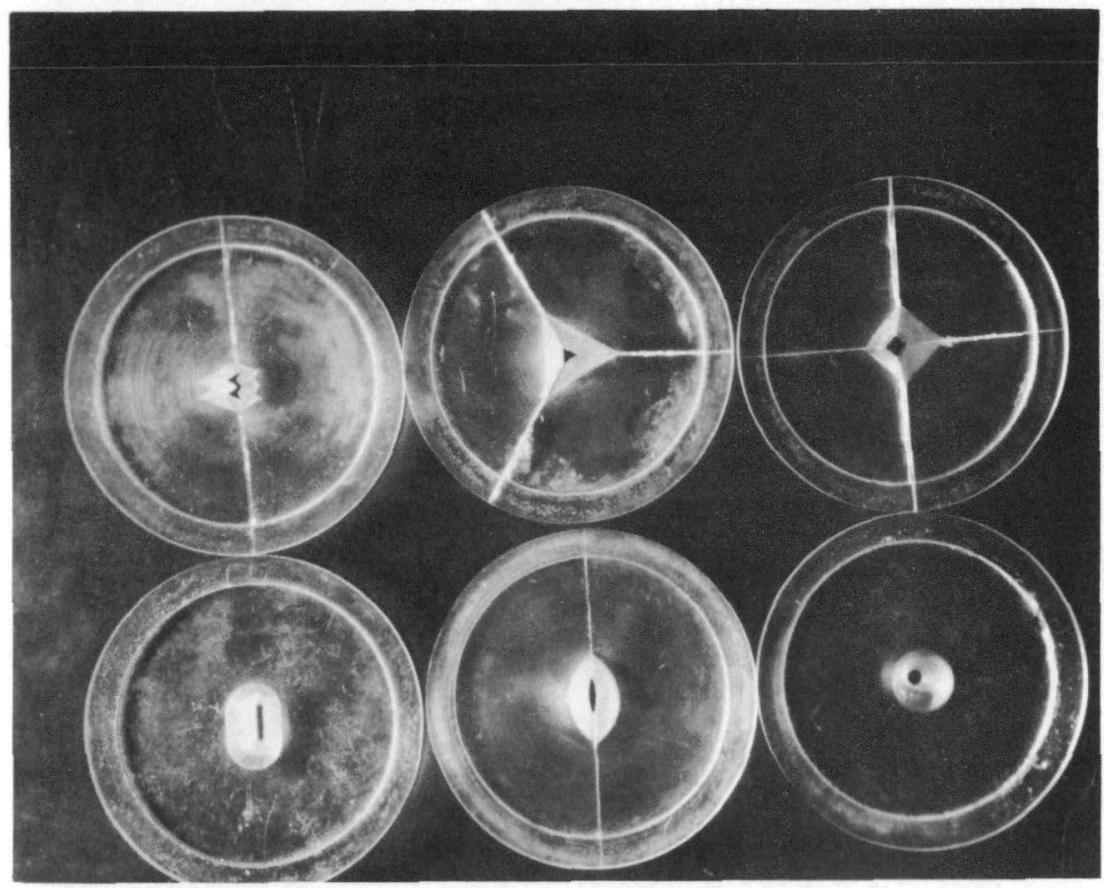

Fig. 3. View of the Test Apertures

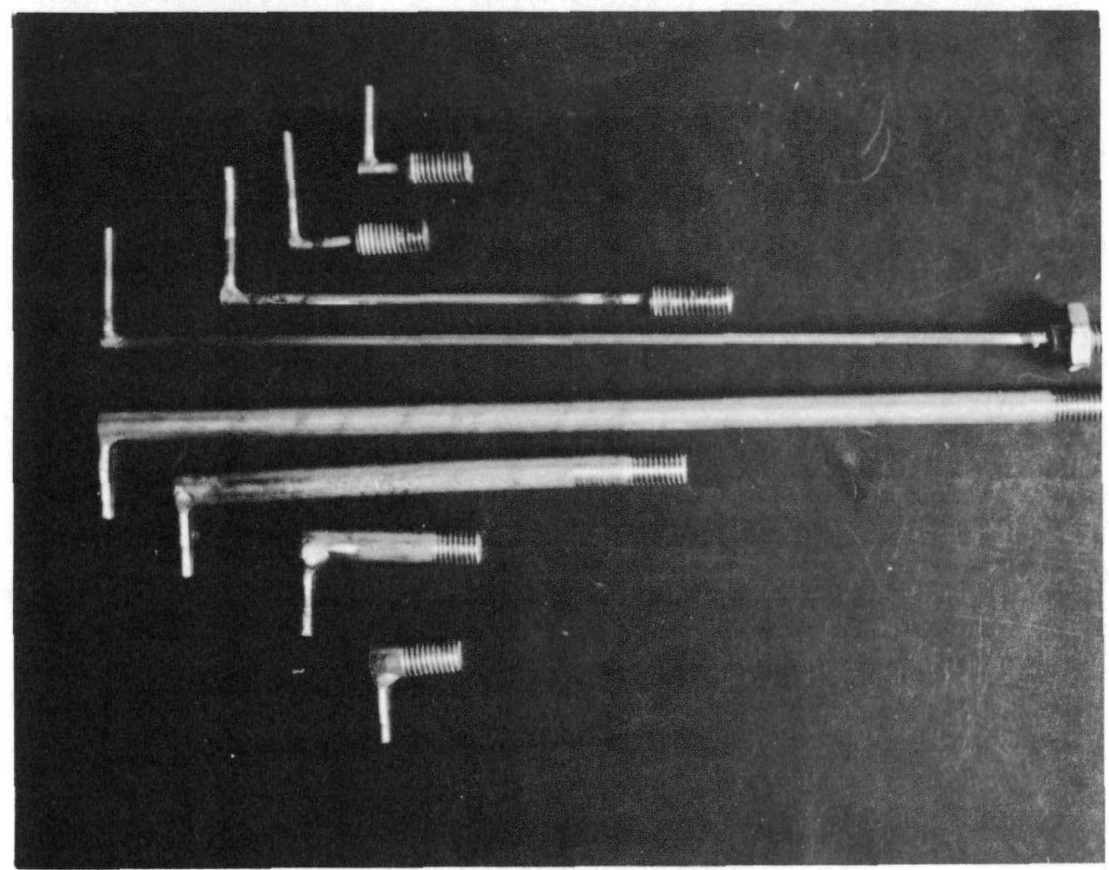

Fig. 4. View of the Test Tubes 
each test tube was carefully filed to provide a plane, sharp cross section. A pressure tap of $\left(\frac{1}{64}-i n\right.$. diameter) was installed a half-pipe diameter from the outlet of each test section. In one of the Lucite flanges concentric tubings were run through so that exit pressure could be measured, by means of the pressure taps installed in the test section and back pressure, by the connection to a manometer.

The vacuum pump was a volumetric displacement type with sliding vanes and had a capacity of about 29 in. Hg under normal operating conditions.

The condenser was a right circular cylindrical container of $\frac{3}{8}$-in.thick Lucite sheet. The inlet was connected by flexible plastic hose to the outlet of the vacuum pump. Dry ice, used as a condensing medium, was placed in a perforated metal tray hanging over the upper portion of the condenser. The condensate was returned by gravity from the bottom of the condenser through a $\frac{1}{2}$-in.-ID pipe to the vessel.

\section{TEST PROCEDURE}

Freon-11 was selected as the working fluid for the following reasons:

1. Refrigerant-11 boils at a temperature slightly above room temperature at atmospheric pressure. This means that a slight reduction in pressure will produce a saturated or supersaturated fluid without adding heat to the system.

2. As it is a recognized heat transfer medium in commercial use, many thermodynamic properties are tabulated.

3. It is nontoxic, noninflammable, and odorless.

4. It is water white in color, facilitating photographic studies.

5. It is easily available and not too expensive.

The saturated or nearly saturated Freon-l 1 was poured into the vessel to about two-thirds full, and dry ice was filled into the top part of the condenser. The vacuum pump was started and, when steady state was reached (that is, a constant discharge rate), the temperature of the liquid Freon-11 in the vessel, initial pressure, exit pressure, back pressure, volume displacement rate of Freon-11 in the vessel, and visual observations of the fluid behavior were recorded. The temperature of the liquid Freon-11 was sensed by a 30-gauge iron-constantan thermocouple immersed in the liquid at the level of the test section.

For measurement of flow rate, the use of orifice and rotameter were found to be impractical, since calibration of two-phase flow for the former 
is difficult and boiling occurs around the floater and wall of the latter. It was, therefore, decided to measure the volume displacement rate by timing a displacement of about $0.08 \mathrm{ft}^{3}$ of liquid, or a drop in liquid level of about 2 in., in most of the tests carried out. This corresponds to a maximum change of 0.1 psi in initial upstream pressure during a run. Since the vessel was open to atmosphere during operation, the upstream pressure can, for all practical purposes, be considered constant. In a few tests even smaller displacements were timed to check the steady-state rate. This method was found sufficient for the accuracy required.

In order to check if critical flow occurred in some of the tube tests, the back pressure was varied by partially closing the inlet valve of the vacuum pump to see if any changes in exit pressure and volume displacement rate occurred.

In the aperture tests, several runs with various back pressures were made and corresponding flow rates and temperatures were measured.

\section{ANALYSIS OF DATA AND APPLICATION}

Figure 5 shows flow rate versus pressure difference curves with the length-to-diameter ratio as parameter for the data obtained on short

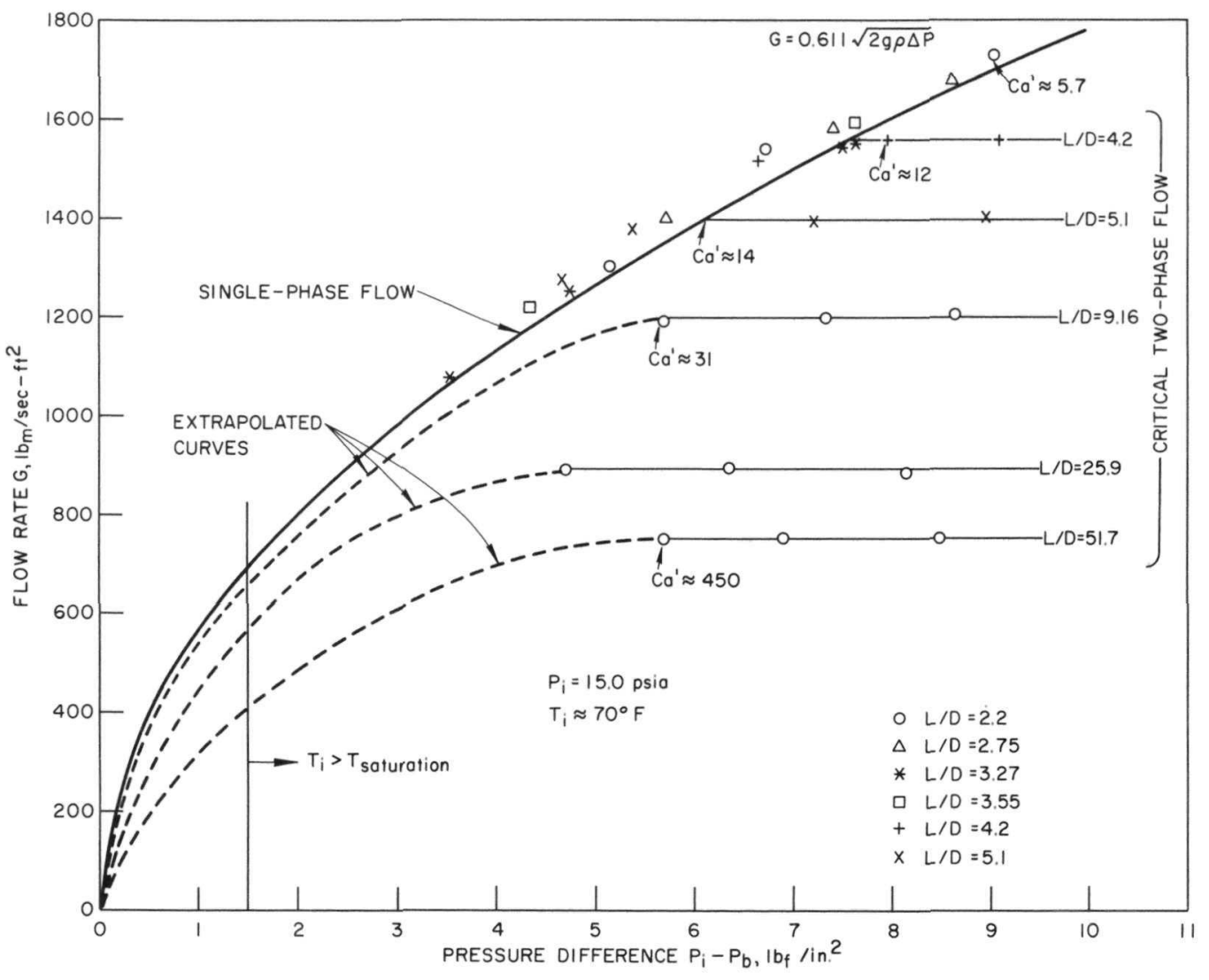

Fig. 5. Data from Short Tubes 
tubes. Also in Fig. 5 are plotted the flow rates calculated from the orifice flow equation with a discharge coefficient equal to 0.611 . It is interesting to note from Fig. 5 that for certain combinations between mass velocity, pressure difference and length-to-diameter ratio the fluid behaves like a single-phase incompressible fluid, although the local pressure is well below the vapor pressure. The initiation of two-phase flow and, if back pressure is low enough, critical flow can be seen from Fig. 5 to depend on G, $\triangle \mathrm{P}$ and $\mathrm{L} / \mathrm{D}$. It seems likely that to a first approximation, combinations of $\mathrm{G}, \triangle \mathrm{P}$ and $\mathrm{L} / \mathrm{D}$ would indicate the transition from single to two-phase flow. The following dimensionless group was chosen to characterize this transition.

$$
\mathrm{Ca}^{\prime}=\frac{2 \mathrm{~g} \Delta \mathrm{P}}{\rho_{\mathrm{i}} \mathrm{u}^{2}}(\mathrm{~L} / \mathrm{D})
$$

This group will be termed the modified cavitation number. The dimensionless group evaluated with initial density $\rho_{i}$, initial velocity $u$, pressure difference of initial and exit pressure, and length-to-diameter ratio $L / D$ are shown in Fig. 6. The significance of this group is that it establishes a criterion for determining single-phase or two-phase flow regimes in short tubes. As indicated in Fig. 6, for modified cavitation number below 10, the fluid exhibits completely metastable single-phase flow. When the modified cavitation number exceeds 14, two-phase flow exists. In the range of $\mathrm{Ca}^{\prime}$ between 10 and 14 , unstable transitional flow occurs. These conclusions from the obtained experimental data were verified by visual observations.

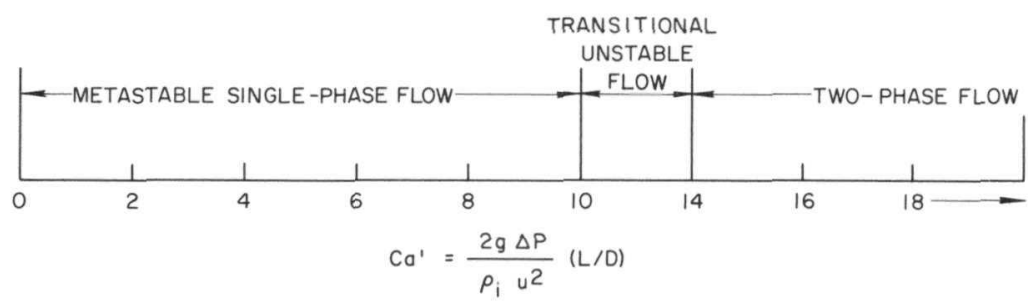

Fig. 6. Correlation Number Determining the Occurrence of Single- and Two-phase Flow Regimes

In Fig. 7 the critical flow rate is plotted versus length-to-diameter ratio for initial pressure equal to 15 psia. It can be seen that for the same initial conditions the critical flow rate is increasing sharply for decreasing length-to-diameter ratio. In most practical situations, the initial and back pressure and L/D ratio of the tube are known. Therefore, if curves like the one in Fig. 7 were available for a variety of initial conditions, one could obtain a correlation for estimating the maximum flow rate. An experimental program is under way to obtain such curves for steam-water for initial pressures up to 2000 psia, and will appear in a later report. 


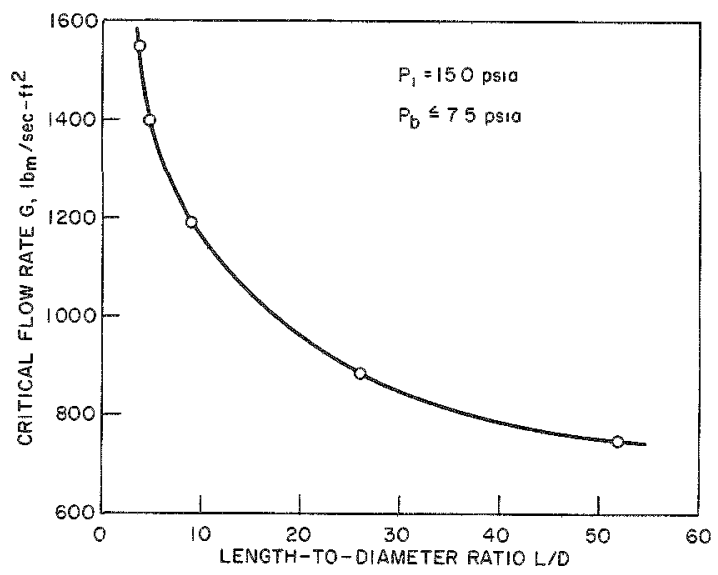

Fig 7

Correlation of Flow Rate and Lengthto-diameter Ratio of Short Tubes

For the tests of apertures, data are plotted in velocity against pres sure difference as in Fig. 8. It can be seen that the Euler numbers of

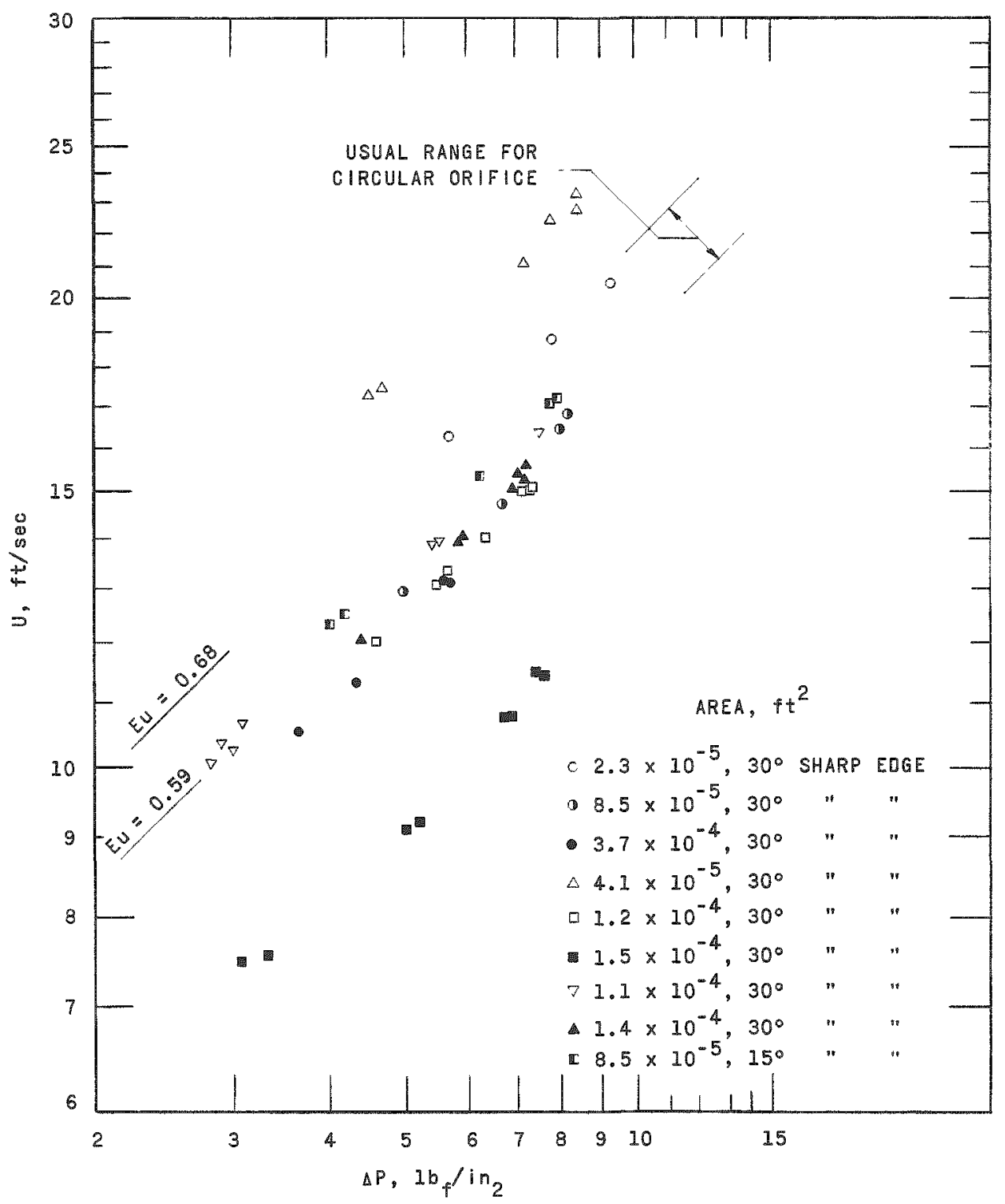

Fig. 8. Euler Number Variation for Various Apertures 
square, rectangular, and eye-shaped apertures exhibit the same characteristics as those of circular ones, but not the triangular and $W$-shaped ones. The former seems to be associated with higher and the latter with lower Euler numbers.

Hence, Fig. 8 becomes a useful tool in determining the rate of flow of saturated or subcooled fluid through a known aperture configuration where upstream pressure and temperature and back pressure are specified.

\section{DISCUSSION}

\section{A. Aperture Tests}

In the introduction, the following question was raised: "does one obtain critical flow when a sudden break in a vessel containing saturated fluid occurs?" A pressure drop is required for the fluid to go through the break or opening. Hence, close to the break (inside the vessel) the vapor pressure becomes higher than the corresponding local pressure, and one could speculate that flashing of the fluid will take place inside the break such that com pressibility is achieved and, hence, cause critical flow if the back pressure is sufficiently low. However, this is not the case in this work. No bubble formation seems to take place, and the fluid leaves the break as a superheated or completely metastable single-phase fluid and remains as a singlephase jet up to $3 \mathrm{ft}$ from the discharge hole. At this point the metastability of the single-phase jet is disturbed either by hitting the before-mentioned $90^{\circ}$ elbow or, due to gravity, the bottom surface of the expansion tube where the fluid flashes instantaneously. It should be mentioned here that this por tion is very much cooled, due to the latent heat of vaporization of Freon-11, whereas the portion of the expansion tube upstream of this point remains fairly close to the room temperature. Maximum superheat of $40^{\circ} \mathrm{F}$ was achieved in these liquid jets. Highex superheats could not be achieved due to the capacity of the vacuum pump. A typical superheated liquid Freon-11 jet, formed from a circular aperture of $\frac{1}{8}-$ in.-ID, is shown in Fig. 9.

In Fig. 10 a close-up view of the superheated liquid jet discharged from an eye-shaped aperture is shown. Here "the vena contracta" of the discharged fluid can be readily observed. In all of the aperture configurations utilized in this work similar single-phase superheat jets were obtained, as shown in Figs. 9 and 10. It is, therefore, concluded that a saturated fluid discharging through an aperture can be described with subcooled singlephase fluid-flow theory. Furthermore, critical flow does not occur under these conditions. The discharge flow rates become, therefore, naturally much larger than one would have expected previous to this work.

In Fig. 8 it is noted that, for a fixed pressure difference, the Euler numbers for triangular, rectangular, square, eye-shaped and $W$-shaped apertures depend on area or equivalent diameters. The larger the diameter 


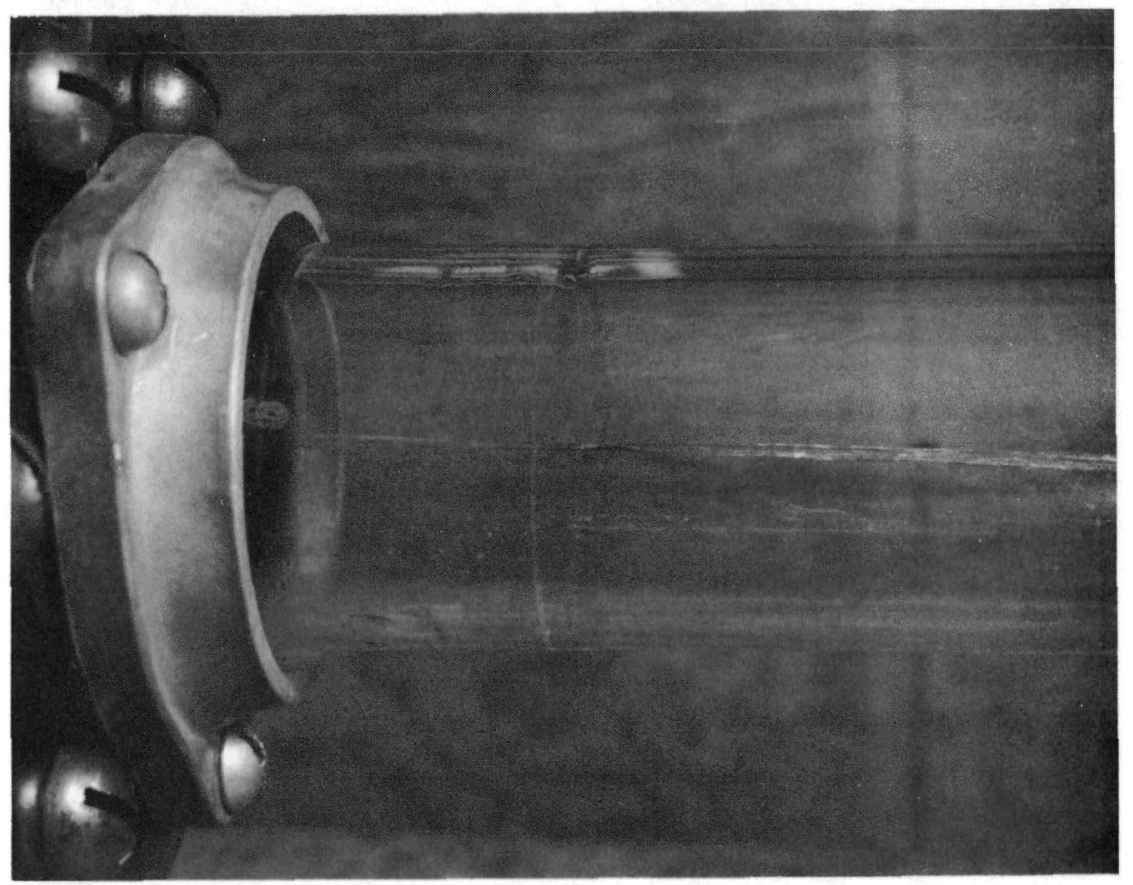

Fig. 9. Photograph Showing the Discharged Fluid from a Circular Aperture

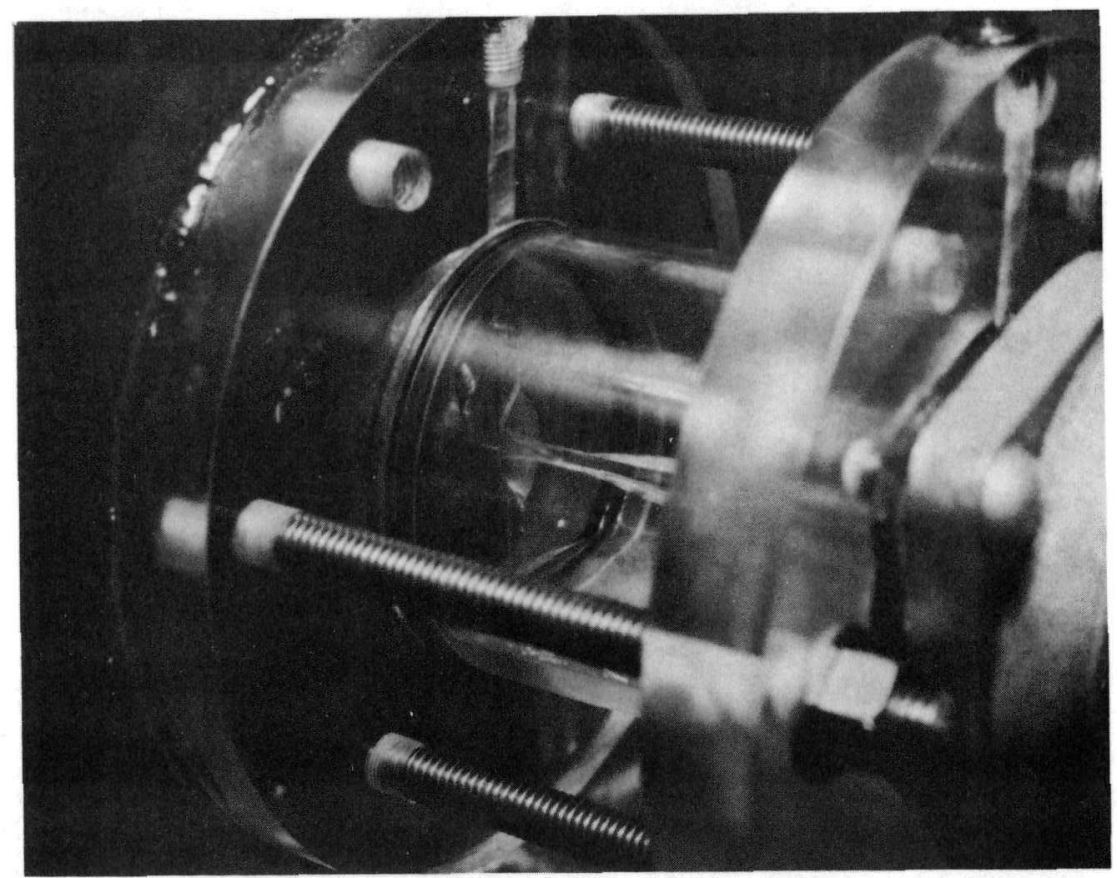

Fig. 10. Photograph Showing the Discharged Fluid from an Eye-shaped Aperture 
becomes, the smaller is the Euler number. This has previously been found to be the case for circular sharp-edge orifices.(12) A similar conclusion was mentioned for rectangular apertures. (11)

B. Short-tube Tests, $\mathrm{Ca}^{\prime}<14$

For modified cavitation numbers below 10, the discharged fluid be haves like a single-phase jet. A typical example is shown in Fig. 11 for a tube with $\mathrm{L} / \mathrm{D}=3$. In this particular run the system possessed a modified cavitation number of approximately 8. It is postulated that any modified cavitation number below 10 will cause the discharge fluid (superheated) to spring free of the sides of the tube. The tube will then function as an orifice. (This is related to the phenomena called "vena contracta.")

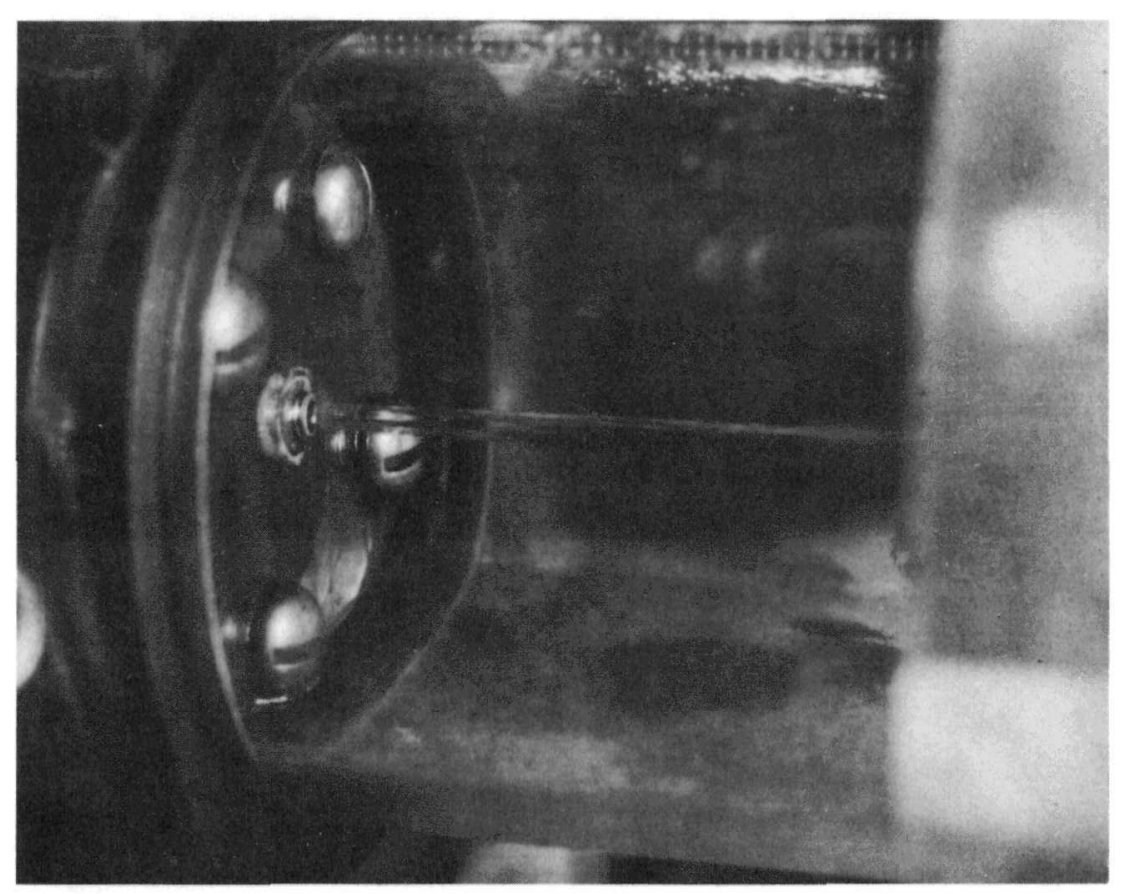

Fig. 11. Photograph Showing the Discharged Fluid from a Tube with $\mathrm{L} / \mathrm{D} \sim 3$ and $\mathrm{Ca}^{\prime} \sim 8$

For a modified cavitation number between 10 and 14 , unstable transitional flow occurs. In this range single- and two-phase flow occur alternately. It is postulated here that the tube flows full at the exit and 
that the contact time between wall and fluid may or may not be large enough to cause flashing and, hence, produce a two-phase flow regime. It should be mentioned here that the behavior of the fluid for this range of modified cavitation numbers is strongly dependent upon how invariant the upstream conditions can be maintained. Figure 12 shows a typical picture of a run in a range of $\mathrm{Ca}$ ' between 10 and 14. Vapor formation in the liquid jet is dis cernible at some instances.

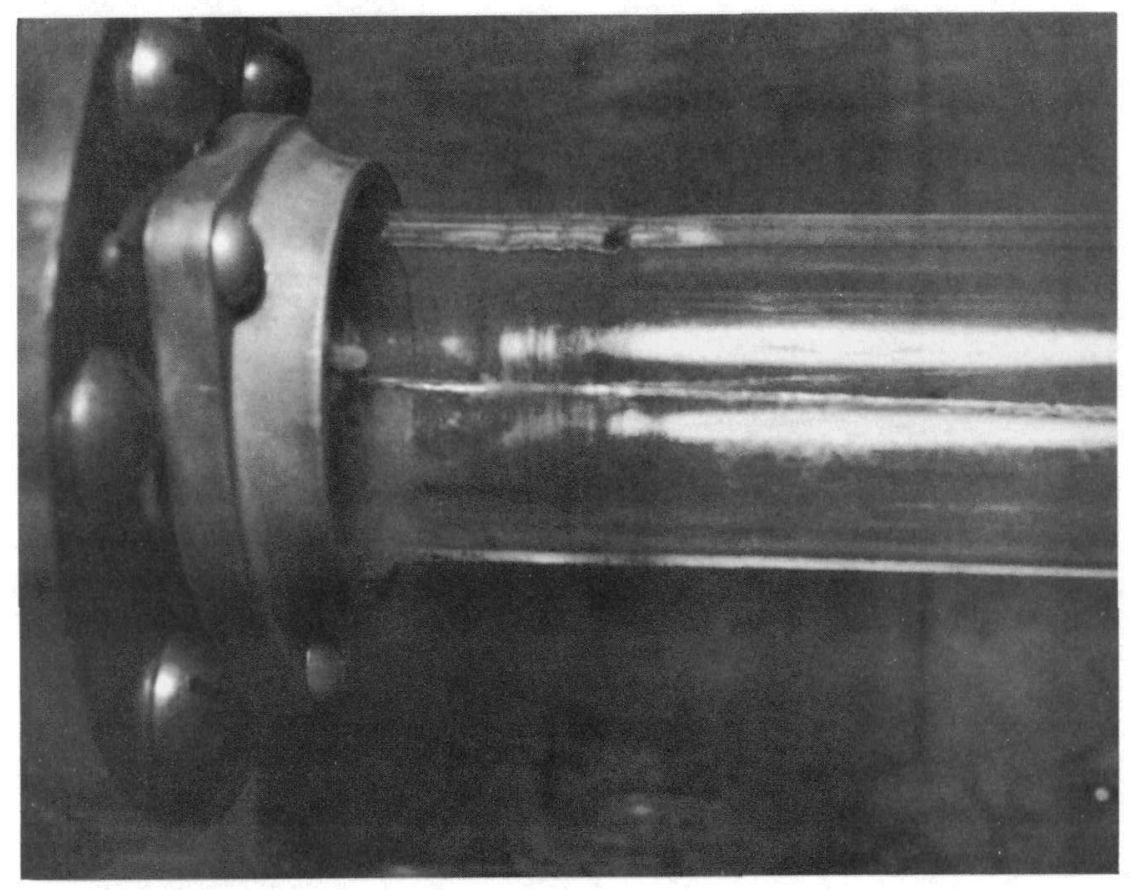

Fig. 12. Photograph Showing the Discharged Fluid from a Short Tube with a Modified Cavitation Number between 10 and 14

Pasqua(9) showed in his data that, for a given pressure difference, the larger the $\mathrm{L} / \mathrm{D}$ ratio, the smaller is the coefficient of contraction. Also, he indicated that the coefficient is inversely proportional to the pressure difference. These statements were confirmed by our findings, as can be seen in Fig. 5.

C. Short Tubes, $\mathrm{Ca}^{\prime}>14$

For a modified cavitation number greater than 14, critical two-phase flow can be achieved if the back pressure is sufficiently low. Figure 13 shows a typical picture of the discharged fluid when critical flow occurs. As mentioned in the introduction, considerable amount of work has been de voted to studies of critical flow. Most of these studies have been made with $\mathrm{L} / \mathrm{D}$ ratios greater than 40 . 


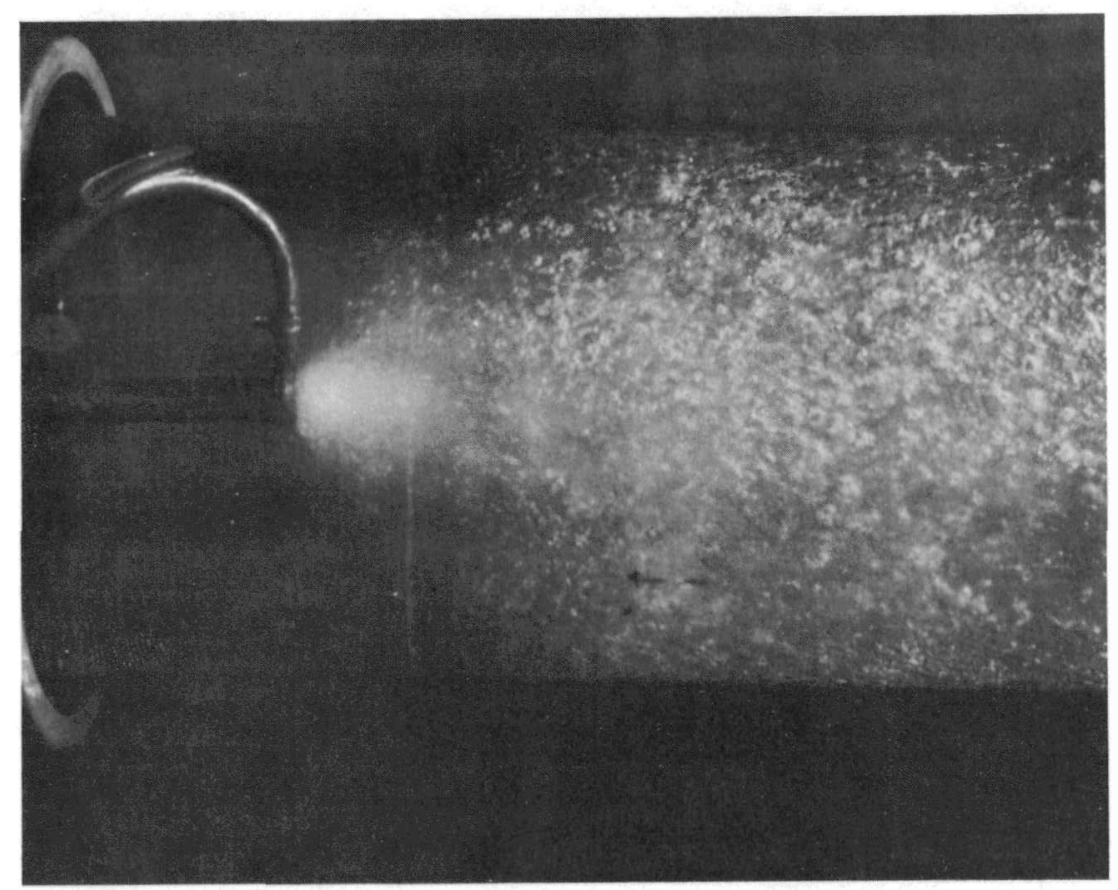

Fig. 13. Photograph Showing the Discharged Fluid from a Short Tube when Critical Flow Occurs

In these earlier tests, a close approach to thermodynamic equilibrium was believed achieved. The Fauske model,(1) based on equilibrium and including slip, predicts these data rather well. This model was, therefore, tested for the critical flow data obtained in this work. The data presented in Fig. 5 for $L / D>20$ can be predicted with this model within \pm 10 percent. As the L/D ratio decreases below 20, the deviation between this separated flow model and the obtained data becomes larger and larger, the predicted values being lower than those obtained. One contributing reason to this is that the contact time is shorter for smaller L/D ratio so that the departure from physical equilibrium is larger. This means that the actual quality of the metastable two-phase flow is much smaller than the quality calculated by assuming thermodynamic equilibrium. Since departure from thermodynamic equilibrium is very difficult to include in a mathematical model, the data were correlated in a restrictive manner as shown in Fig. 7. It can, therefore, be concluded that, for $\mathrm{L} / \mathrm{D}<20$, metastable two-phase critical flow definitely occurs.

\section{CONCLUSIONS}

The experiment covered a range of modified cavitation numbers between 0 and 500, and of length-to-diameter ratio between 2 and 55. Within the limits of experimental precision, the following conclusions may be drawn: 
1. Saturated or nearly saturated Freon-11 discharged through various apertures behaves like a single-phase incompressible fluid.

2. Apertures with an irregular configuration produce essentially the same behavior as those of circular shapes, except for the triangular and $\mathrm{W}$-shaped ones. The triangular aperture yields higher, whereas the W-shaped one yields lower, Euler numbers.

3. The modified cavitation number is a useful criterion for determining when single- or two-phase flow regimes occur in short tubes.

4. The "critical" modified cavitation number is about 14 .

5. A simple method to predict discharge rates from short tubes is presented in Figs. 7 and 8.

6. For $\mathrm{L} / \mathrm{D}>20$, the Fauske model can be utilized to predict critical flow rates.

7. For $\mathrm{L} / \mathrm{D}<20$, the experimental flow rates are greater than predicted by the Fauske model. The difference increases for decreasing $\mathrm{L} / \mathrm{D}$ ratio.

8. The main discrepancy between the predictions of the Fauske model and the data for $\mathrm{L} / \mathrm{D}<20$ is believed to be caused by existing nonequilibrium conditions in the two-phase flow system.

\section{ACKNOW LEDGEMENTS}

The authors are indebted to the following people:

Matthew P. Gats, who assisted in most of the testing and prepared all the photographs;

Peter Zaleski and Elmer Gunchin, who constructed most of the test equipment;

Branko Dokmonovic', for his assistance in some of the computational and testing work,

Michael Petrick, for helpful suggestions during the course of this investigation; and to

H. S. Isbin and P. A. Lottes, for their encouragement and active interest. 


\section{BIBLIOGRAPHY}

1. H. K. Fauske, Contribution to the Theory of Two-phase, Onecomponent Critical Flow, ANL-6633 (Oct 1962).

2. H. K. Fauske, Critical Two-phase, Steam-Water Flows, 1961 Proc. Heat Transfer and Fluid Mech. Inst., Stanford University Press, Stanford, p. 79.

3. H. S. Isbin, J. E. Moy, and A. J. R. Gruz, Two-phase, Steam-Water Critical Flow, A.I.Ch.E. Journal, 3, 361-365(1957).

4. H. S. Isbin, H. K. Fauske, T. Grace, and I. Garcia, Two-phase SteamWater Pressure Drops for Critical Flows, Symposium on Two-phase Fluid Flow, February 7, 1962, Institution of Mech. Eng., London, England.

5. D. W. Faletti, Two-phase Critical Flow of Steam-Water Mixtures, Ph.D. Thesis, Univ. of Washington (1959).

6. F. R. Zaloudek, The Low Pressure Critical Discharge of SteamWater Mixtures from Pipes, HW-68934 REV (March 1961).

7. R. James, Steam-Water Critical Flow through Pipes, Preprint of Thermodynamics and Fluid Mechanics Group, The Inst. of Mech. Eng., June, 1962.

8. J. F. Bailey, Metastable Flow of Saturated Water, Trans. ASME, 73, 1109-1116 (Nov 1951).

9. P. F. Pasqua, Metastable Flow of Freon-12, Refrigerating Engineering, 61, 1084A-1088,1131(Oct 1953).

10. H. C. Simpson and R. S. Silver, The Theory of One-dimensional, Twophase Homogeneous Non-equilibrium Flow, Symposium on Two-phase Fluid Flow, Inst. of Mech. Eng., Feb. 7, 1962.

11. H. S. Isbin and G. R. Gavalas, Two-phase Flow through an Aperture, Proceedings of the 1962 Heat Transfer and Fluid Mechanics Institute, pp. 126-139.

12. R. L. Daugherty and A. C. Ingersoll, Fluid Mechanics, Fifth Edition, McGraw-Hill Book Co., New York (1954), p. 125. 